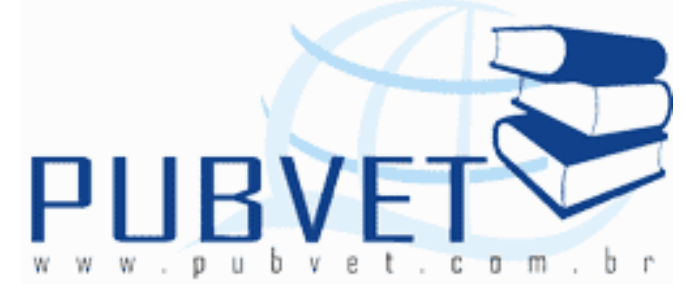

PUBVET, Publicações em Medicina Veterinária e Zootecnia.

Disponível em: <https://doi.org/10.31533/pubvet.v02n10a396>.

\title{
Termorregulação em búfalos manejados em ambiente tropical
}

João Batista Freire de Souza Junior ${ }^{1}$, Hérica Girlane Tertulino Domingos ${ }^{1}$, Rosiane Batista Silva ${ }^{1}$, Renata Nayhara de Lima ${ }^{2}$

1. Núcleo de Estudo e Pesquisa em Biometeorologia e Bem-Estar Animal (NUBEA) da Universidade Federal Rural do Semi-Árido (UFERSA).

2. Discente do Curso de Zootecnia da Universidade Federal Rural do SemiÁrido (UFERSA).

\section{Resumo}

O Bubalino é mais sensível que o bovino à radiação solar direta e ambientes com altas temperaturas. Apesar da adaptabilidade às mais variadas condições ambientais, os búfalos possuem particularidades estruturais e funcionais específicas. O controle da temperatura em um dado organismo é chamado de Termorregulação. O balanço de energia térmica presente em um animal homeotérmico, tal como um bubalino e dado pela taxa de produção de calor liberada nos processos metabólicos, ou seja, na oxidação dos alimentos ou das reservas corporais menos o ganho de calor através da radiação de ondas curtas, as trocas de energia térmica por radiação de ondas longas e os fluxos de calor por condução, por convecção respiratória e por convecção na superfície do pelame que pode se mecanismos de ganho ou perda de calor, 
onde irá depender da diferença de temperatura entre animal e ambiente, e as perdas de calor latente através da evaporação cutânea e respiratória (SOUZA $\mathrm{JR}, 2008)$.

\section{Thermoregulation in buffalo managed in tropical environment}

\section{Abstract}

The buffalo is more sensitive to the veal to direct sunlight and environments with high temperatures. Despite the adaptability to a wide variety of environmental conditions, the buffalo have specific structural and functional features. The control of the temperature in a given body is called Thermoregulation. The balance of heat present in an animal as a buffalo and given the rate of production of heat released in metabolic processes, or the oxidation of food or the reservations of the gain less body heat through shortwave radiation, The exchange of heat by long-wave radiation and the flow of heat by conduction, convection by respiratory and by convection on the surface of pelame mechanisms that can gain or loss of heat, which will depend on the temperature difference between animal and environment, and the loss of latent heat through the skin and respiratory evaporation.

\section{Introdução}

Termorregulação é o processo de controle da temperatura em um sistema físico qualquer. Como a função corpórea resulta de processos físicos e químicos sensíveis a alterações na temperatura, os animais utilizam várias estratégias para regular a temperatura de seus tecidos. Caso de deixe a temperatura corpórea baixar muito, os processos metabólicos ficam tão lentos que a função corpórea cessa. Por outro lado, um aumento na temperatura além do valor normal em torno de 38 a $45^{\circ} \mathrm{C}$ pode desnaturar proteínas e também ser fatal. (CUNNINGHAM, 1993).

O búfalo (Bubalus bubalis L.), originário do continente asiático e de 
algumas regiões da Itália, é hoje encontrado em amplo espaço geográfico em vários continentes. Foi introduzido no Brasil ao final do século XIX, na Ilha de Marajó, Estado do Pará, estando atualmente disseminado em todo o País. Segundo Marques e Cardoso (1997), estima-se que o rebanho nacional seja formado por 3 milhões de cabeças. Apesar da adaptabilidade às mais variadas condições ambientais, os búfalos possuem particularidades estruturais e funcionais específicas, como forte concentração de melanina na pele e no pêlo, baixa quantidade de glândulas sudoríparas, baixa densidade de pêlos e pele escura, sendo, portanto, especialmente sensíveis à radiação solar (Harvey, 1963). Assim, os búfalos utilizam outros meios de aclimatação aos trópicos, como a via respiratória, com alta habilidade fisiológica para eliminar o excesso de calor (Villares, Ramos e Rocha, 1979).

Os efeitos do estresse térmico no bem-estar de animais intensivamente manejados têm sido largamente discutidos no meio acadêmico, a despeito de animais criados extensivamente não receberem a mesma atenção com relação ao estresse. $O$ calor é um dos principais fatores restritivos na produção animal nos trópicos e, como resultado da mudança drástica nas funções biológicas, pelo estresse térmico, ocorre o prejuízo do desenvolvimento do animal, de sua produção de carne e leite, reprodução e capacidade de trabalho. Apetite, ingestão, eficiência alimentar e utilização do alimento são prejudicados (MARAI \& HABEEB, 1998). Ao mesmo tempo, ocorre aumento da temperatura retal, da sudação e da freqüência respiratória, redução das perdas de água nas fezes e na urina, disfunções no metabolismo de proteína, energia e minerais, assim como distúrbios em reações enzimáticas e secreção de hormônios.

Em resposta ao estresse térmico, mamíferos ajustam processos físicos, bioquímicos e psicológicos na tentativa de conter os efeitos negativos do estresse e manter o equilíbrio térmico. A maioria dos ajustes feitos por um animal envolve dissipação do calor para o ambiente e redução da produção do calor metabólico (TITTO, 1998). O resultado final de todas essas mudanças será a limitação de crescimento, de produção de leite e de reprodução (SILVA, 2000), que certamente gerarão problemas de ordem econômica ao produtor 
desses animais.

\section{Particularidades dos bubalinos}

O Bubalino é mais sensível que o bovino à radiação solar direta e ambientes com altas temperaturas. Apesar da adaptabilidade às mais variadas condições ambientais, os búfalos possuem particularidades estruturais e funcionais específicas. A epiderme é mais grossa que a de bovinos e usualmente escura, em virtude da alta concentração de melanina (FAO, 1991). O número de pêlos/cm2 da superfície corporal decresce com a idade, tornando o animal quase glabro na idade adulta. Os pêlos são relativamente longos e grossos e se implantam na pele, associados às glândulas sudoríparas e sebáceas, formando o aparelho pilo-sebáceo-músculo-sudoríparo (Villares et al., 1979b).

Sob reduzida densidade de pêlos, não se forma uma camada de ar isolante sobre a pele, como acontece nos bovinos, favorecendo, portanto, a dissipação do calor corporal. Por outro lado, se a pele escura protege os animais da radiação ultravioleta do sol, a ausência de uma camada de pêlos reflectiva sobre a pele torna o animal susceptível às radiações infravermelhas que são absorvidas devido à cor escura da pele. Dessa forma, o búfalo é muito sensível quando exposto à radiação solar direta (Harvey, 1963), mas em condições de sombra, ele atua como um típico "corpo negro" radiador de calor, pois recupera seu equilíbrio térmico rapidamente (Mason, 1974).

Menor número de Glândulas Sudoríparas/Unidade de área de pele implicando em maior dificuldade de dissipar calor através da sudorese. As glândulas sudoríparas são do tipo apócrina, com uma densidade por unidade de área da superfície corporal 10 vezes menor que nos bovinos (Mason, 1974). Devido à escassez de glândulas sudoríparas, a perda de calor pelas vias cutâneas, que é a maior via de dissipação térmica para a maioria dos animais nos trópicos (Chutikul, 1975), é menor em bubalinos que nos bovinos (Loypetjra et al., 1987), entretanto, os búfalos apresentam altas taxas de 
sudação sob condições de temperaturas elevadas (Pant \& Roy, 1982).As glândulas sebáceas dos bubalinos são volumosas e possuem maior atividade secretória que as de bovinos. No calor, o sebo por elas produzido se fluidifica tornando a pele mais oleosa e favorecendo a reflexão da radiação solar (Shafie, 2005).

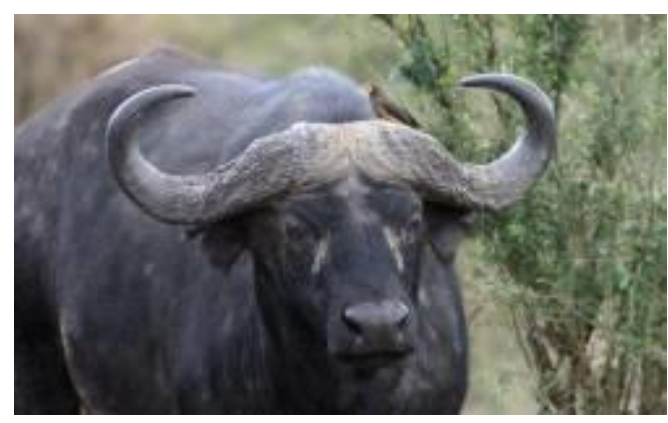

Figura 1. O búfalo (Bubalus bubalis L.).

Além disso, a camada da epiderme da pele dos bubalinos é grossa, o que resulta na redução da perda calor por condução e irradiação. O búfalo é adaptado aos climas quentes e úmidos dos trópicos e sub-trópicos. Segundo MISTRA et al. (1963), bubalinos são sensíveis em temperaturas acima de $36,1^{\circ} \mathrm{C}$ e à exposição direta ao sol, apresentando alterações fisiológicas acentuadas, para a adaptabilidade ao ambiente.

Assim, nessas condições, aumentam a temperatura corporal, a freqüência respiratória e cardíaca, deprimindo a atividade metabólica e a atividade da glândula tireóide, com conseqüente redução da ingestão de alimentos e do nível de produção, ou seja, pior desempenho produtivo. Mesmo assim, o búfalo é adaptado aos climas quentes e úmidos dos trópicos e subtrópicos. Esta adaptabilidade é atribuída à natureza semi-aquática, procurando água e mantendo o corpo submerso a fim de reduzir o efeito do calor.

Em virtude das características da pele, como baixo número de glândulas sudoríparas e reduzida quantidade de pêlos, o búfalo procura a imersão na água ou charfudação na lama para manter a homeotermia (Loypetjra et al., 1987) e se livra do estresse pelo calor. Apesar disso, a imersão em água não é essencial para a sobrevivência dos animais dessa espécie, como mostraram 
pesquisas realizadas na Malásia e Flórida (NRC, 1981) e na Austrália (Tulloch \& Litchfield,1981). Esses estudos mostraram que búfalos podem crescer normalmente sem a presença de água para se banharem, desde que sombra adequada esteja disponível.

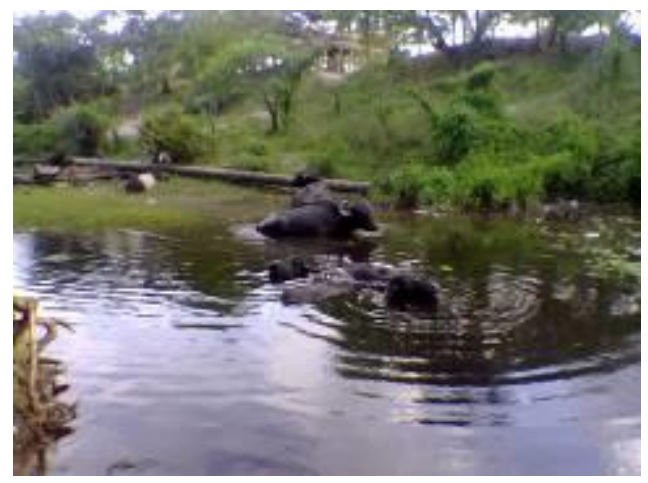

Figura 2. Búfalos em água de imersão para minimizar o estresse calórico.

Em condições naturais, os bubalinos procuram a água para imersão sempre que a temperatura do ar é superior a $29,0^{\circ} \mathrm{C}$ (FAO, 1991). No verão catarinense a atividade predominante dos búfalos na parte da manhã entre $8 \mathrm{e}$ 11 horas foi o banho e à tarde o pastoreio (Machado Filho et al., 1989). $\mathrm{Na}$ Índia, com livre acesso a lagoas durante todo dia, os animais procuraram a água entre 9 e 10 horas e permaneceram imersos durante 5,5 a 6 horas, com interrupção às 12 horas para pastejo (Mason, 1974).

Onde não existe água, a presença de sombra tem efeito marcante, pois a evaporação pelo trato respiratório é um eficiente mecanismo de perda de calor em bubalinos.

\section{Características de adaptação}

Estes animais possuem baixa eficiência na perda de calor pelas vias cutâneas (Chikamune et al., 1986), sendo a via respiratória de grande relevância na dissipação térmica (Villares et al., 1979a). Dollah \& Robertshaw (1991) concluíram que a taxa de sudação é um bom indicador de adaptabilidade de búfalos ao calor. Por outro lado, a temperatura retal tem 
sido considerada o melhor indicador de estresse calórico (Blackshaw \& Blackshaw, 1994), mas estudo com vacas leiteiras mostrou que, nesse sentido, a freqüência respiratória foi superior (Azevedo, 2004).

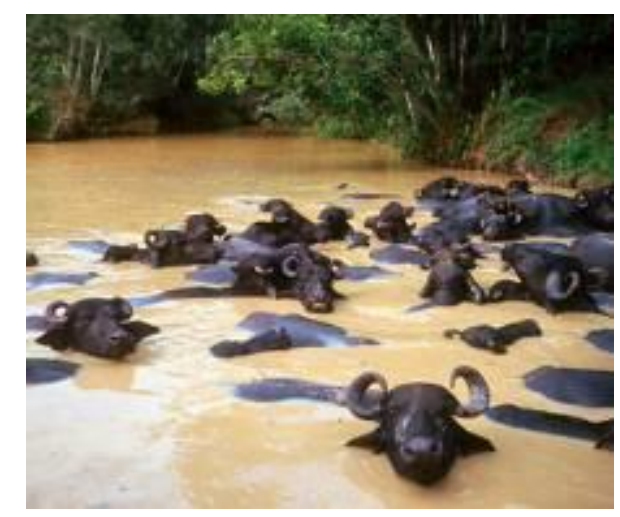

Figura 3. A água torna a perda de calor na superfície cutânea eficiente.

Assim, alterações na temperatura retal e na freqüência respiratória têm sido os dois parâmetros mais utilizados como medida de conforto animal e adaptabilidade a ambientes adversos, ou como medida da eficácia de modificações ambientais (Hemsworth et al., 1995).

Tabela 1. Efeitos do clima sobre diferentes idades.

\begin{tabular}{ccc}
\hline \multirow{2}{*}{ Idade } & \multicolumn{2}{c}{ Temperatura retal $\left({ }^{\circ} \mathrm{C}\right)$} \\
& $7: 00$ & $16: 00$ \\
\hline$<1$ ano & 38,7 & 39,1 \\
1 a 2 anos & 38,2 & 38,5 \\
$>2$ anos & 38,2 & 38,5 \\
Adultos & 38,2 & 38,4 \\
\hline
\end{tabular}

De acordo com a tabela 1 , os búfalos jovens são os que mais são afetados pelas altas temperaturas.

Os animais homeotérmicos, como os bubalinos, são aqueles que conseguem manter constante sua temperatura corporal, dentro de estreitos limites, apesar das grandes variações na temperatura ambiente. A temperatura corporal resulta do equilíbrio entre o ganho e a perda de calor do 
corpo (balanço de calor), isto é, do equilíbrio entre a quantidade de calor produzida no organismo, ou por ele absorvida, e a quantidade liberada para o ambiente.

Quando o animal tem um ganho líquido de calor do metabolismo ou do ambiente, surge a hipertermia e a temperatura corporal ultrapassa o limite superior normal. Para manter a homeotermia o animal adota respostas fisiológicas que poderão levar à queda na produção e na eficiência reprodutiva. Dessa forma, o desempenho animal em ambientes quentes está diretamente relacionado com sua eficiência em dissipar o calor corporal excedente, preservando o seu equilíbrio térmico.

O clima tem efeito sobre a temperatura retal, a taxa de respiração e a taxa de circulação dos animais. Estes índices alteram-se no dia, mês e ano (sazonal). O aumento na temperatura ambiental (dia/ano): causa um aumento na temperatura retal, na taxa de respiração e na taxa de circulação. A exposição constante do búfalo a elevadas temperaturas principalmente nos meses de verão pode ser prejudicial aos índices produtivos e reprodutivos. Se os animais não tiverem acesso à abrigos, lamaçal, aspersão de água, etc., o consumo de alimento e a taxa de crescimento diminuem, com possível perda de peso.

Tabela 2. Índices Fisiológicos Médios em Bubalinos

\begin{tabular}{cccc}
\hline Idade (anos) & $\begin{array}{c}\text { Temp. Corp. } \\
\left({ }^{\circ} \mathrm{C}\right)\end{array}$ & $\begin{array}{c}\text { Taxa de } \\
\text { Resp./Min }\end{array}$ & Taxa Circ/Min \\
\hline 1 & 38,5 & 29 & 69 \\
2 & 38,3 & 26 & 60 \\
3 & 38,2 & 25 & 59 \\
4 a 8 & 38,0 & 24 & 56 \\
\hline
\end{tabular}

O bubalino tem maior taxa de substituição de água no corpo que o Bos taurus e Bos indicus. É também menos eficiente na utilização de água, evidenciado pelo alto consumo de água/Kg de MS ingerida, maior volume 
urinário e menor de reabsorção de água pelos rins. Isto é muito importante, principalmente no verão.

Em búfalas em lactação, a exigência no consumo de água aumenta, podendo diminuir a produção de leite com mudanças na composição (redução da \% de sólidos gordurosos e \% de sólidos não gordurosos). Ocorre aumento da taxa metabólica, pelo aumento do consumo de MS, o que aumenta a ${ }^{\circ} \mathrm{C}$ corporal.

\section{Tabela 3. Efeito da condição reprodutiva sobre a temperatura corporal e taxa de respiração em bubalinos.}

\begin{tabular}{ccc}
\hline $\begin{array}{c}\text { Condição } \\
\text { Prenhez - Lactação }\end{array}$ & $\begin{array}{c}\text { Temp. Corp. } \\
\left({ }^{\circ} \mathrm{C}\right)\end{array}$ & $\begin{array}{c}\text { Taxa Resp. } \\
/ \mathrm{min}\end{array}$ \\
\hline Não - Não & 38,12 & 19,9 \\
Não - Sim & 38,27 & 21,9 \\
Sim - Não & 38,35 & 22,9 \\
\hline
\end{tabular}

\section{Estacionalidade reprodutiva dos Bubalinos no Brasil}

A reprodução é a atividade biológica mais importante para qualquer espécie animal, pois a partir dela são originados os indivíduos da próxima geração, o que garante a sobrevivência da espécie no meio. Nas criações comerciais, a reprodução é atividade multiplicadora dos rebanhos e, na pesquisa, gera uma interface com trabalhos de seleção e melhoramento genético.

Nas regiões mais distantes da linha do Equador, no sentido norte ou sul, o búfalo do rio (Bubalus bubalis) se comporta como um animal poliestral sazonal de dias curtos, apresentando interrupção da ciclicidade durante o verão, quando a luminosidade diária é maior. Contudo, nas regiões próximas ao Equador, as fêmeas bubalinas são animais de comportamento poliestral 
contínuo, ou seja, ciclam durante todo o ano (Vale e Ribeiro, 2005). Estudos sobre a distribuição de partos em búfalas demonstram que essa característica depende significativamente de fatores ambientais locais.

No Brasil, os animais criados na região do Vale do Ribeira, no município de Registro-SP (24030'07" de Latitude Sul e 47050'54" de Longitude Oeste), apresentam concentração de parições entre os meses de fevereiro a abril (Baruselli, 1993), sendo 57,93\% dos animais nascidos neste período (Reichert et al., 2001). Já no nordeste brasileiro, no município de Paracuru, Estado do Ceará, (3045'59" de Latitude Sul e 39014'36"de Longitude Oeste), a maior concentração de partos ocorre no primeiro semestre do ano, com 79,3\% dos eventos concentrados entre janeiro e junho, época de maior pluviosidade local (Sampaio Neto et al., 2001). As concepções se dão, portanto, sob condições locais, nos meses de março a agosto.

$\mathrm{Na}$ Amazônia brasileira, de acordo com a localização geográfica da criação, o padrão de parições se altera. No Estado do Pará, em criações na terra firme, as parições concentram-se no primeiro semestre do ano, com maiores índices nos meses de abril a agosto, enquanto nas áreas de várzeas os partos se concentram de setembro a dezembro (Ribeiro, 2002). Dados oriundos do rebanho experimental da Embrapa, criado na região do baixo Amazonas, no município de Monte Alegre-PA $\left(2^{\circ} 0^{\prime} 30^{\prime \prime}\right.$ de Latitude Sul e $54^{\circ} 4^{\prime} 13^{\prime \prime}$ de Longitude Oeste), demonstram que aproximadamente $78 \%$ dos nascimentos ocorrem entre os meses de julho a dezembro (Cassiano et al., 2003). Nesse local, o rebanho é mantido em sistema de integração entre várzea e terra-firme. A sazonalidade dos partos revela que o maior número de concepções ocorre entre os meses setembro e fevereiro, exatamente quando os animais ocupam as áreas de várzea, que começam a ser descobertas pelas águas em virtude da vazante do rio Amazonas. Nesta época, os campos nativos de várzea apresentam excelentes condições para a exploração pecuária, onde é evidenciada a abundância de forrageiras de bom valor nutritivo, às quais os animais passam a ter acesso.

Segundo Marques (1991), em 5.515 observações de partos em búfalas 
criadas em rebanhos localizados nos Estados do Pará, Paraná, Rio Grande do Sul e São Paulo, houve maior concentração de parições entre março e maio $(49,54 \%)$, valor que superou os registros dos períodos de dezembro a fevereiro $(34,84 \%)$, junho a agosto $(12,63 \%)$ e setembro a novembro $(2,99 \%)$.

Em média, as búfalas apresentaram idade à primeira cria de 37,94 \pm 5,53 meses, período de serviço de 94,69 $\pm 84,19$ dias e intervalo de partos de $404,52 \pm 84,28$ dias. As estimativas de herdabilidade para essas características foram, respectivamente, de 0,249 $\pm 0,113 ; 0,039 \pm 0,033$ e $0,096 \pm 0,046$. A eficiência reprodutiva obtida foi de $87,86 \pm 3,36 \%$, confirmando o bom desempenho dos rebanhos estudados e o grande potencial dos bubalinos para a reprodução, uma vez que todos os rebanhos estudados mantinham seus animais a pasto, e alguns com suplementação de volumoso na época da seca. Os baixos valores de herdabilidade obtidos indicam que o meio ambiente exerce uma importante influência sobre as características reprodutivas dos bubalinos. A precocidade ao primeiro parto poder ser reduzida através de um trabalho bem orientado de seleção, associado a boas práticas de manejo do rebanho, enquanto o intervalo do parto ao primeiro cio fértil também pode ser reduzido com a adoção de um manejo adequado.

\section{Agentes estressores e importância na nutrição}

Considerando os sistemas de produção atualmente adotados para a criação de bubalinos, os fatores ambientais que maiores impactos apresentam sobre a reprodução dos animais são a nutrição dos animais, o clima e suas variações e os hábitos de manejo de cada propriedade.

Os fatores nutricionais são importantes tanto para o estabelecimento da puberdade quanto para a manutenção da ciclicidade ovariana, o reinício da ciclicidade no pós-parto e a manutenção da gestação. Por isso, a condição corporal das búfalas no momento do parto é de extrema importância para a eficiência reprodutiva do rebanho. De acordo com Marques (1991), o cuidado 
no manejo nutricional de fêmeas prenhes nos últimos meses de gestação e, principalmente, no período pós-parto, deve ser redobrado, uma vez que o valor estimado da herdabilidade para o período de serviço em búfalas é baixo $(0,039 \pm 0,033)$, o que indica que essa variável é altamente sujeita a variações pelas modificações de manejo.

Segundo Hegazy et al. (1994), búfalas consideradas magras no momento do parto (escore 2 a 2,5; escala de 1 a 5), quando comparadas com búfalas de escore moderado (escore 3 a 3,5), apresentam atraso na primeira ovulação pós-parto $(62,9$ dias versus 47,2 dias; $P<0,05)$, maior intervalo de dias em aberto $(95,3$ dias versus 81,5 dias; $P<0,05)$ e requerem um número maior de serviços por concepção $(1,7$ versus 1,25 serviço; $P<0,05)$. Por isso, 0 máximo desempenho reprodutivo é observado quando os animais se encontram com escore 3,5 ao parto e entre 3 e 3,5 ao momento da inseminação, devendo esses escores ser considerados como metas para se obter a máxima fertilidade em rebanhos bubalinos.

Devido à inter-relação entre a nutrição dos animais e os resultados na reprodução, a suplementação dos animais em períodos mais críticos do ano tem se mostrado uma estratégia interessante para o aumento nos índices reprodutivos de rebanhos bubalinos. Contudo, a suplementação com uréia deve ser usada com algumas restrições.

O impacto desse tipo de suplementação na reprodução foi descrita por Campanille et al. (2006), que relacionaram a condição corporal e a taxa sangüínea de uréia de 150 búfalas da raça Mediterrâneo em lactação, alimentadas com dieta contendo $14,8 \%$ de proteína bruta e a relação carboidratos não estruturais/proteína bruta 2,14. As búfalas foram inseminadas em tempo fixo e a probabilidade de gestação das fêmeas foi de $46,7 \%$, sendo que esses níveis foram mais baixos para búfalas com escore corporal menor que 6 e maior que 7,5 (em escala de 1 a 9). Isso indica que as fêmeas em estados mais extremos de condição corporal sofreram mais com os efeitos negativos do desbalanço nutricional. $\mathrm{O}$ alto nível de uréia sanguínea das búfalas fez com que a probabilidade de uma búfala se tornar gestante 
reduzisse para $25 \%$. Esses achados científicos indicam que incrementos nos níveis sanguíneos de uréia em búfalas estão associados com redução na fertilidade.

\section{Efeitos do estresse térmico sobre a fisiologia reprodutiva das}

\section{fêmeas}

A intensidade da radiação solar afeta diretamente o comportamento e a fisiologia dos animais domésticos e determina a sua adaptabilidade ao ambiente físico (Zhengkang et al., 1994). Segundo Titto et al. (1998), os mamíferos ajustam seus processos físicos, bioquímicos e psicológicos na tentativa de conter os efeitos negativos do estresse, o que envolve dissipação do calor para o ambiente e redução da produção do calor metabólico. Como exemplo marcante, podem ser citadas as diferenças no comportamento reprodutivo das fêmeas bubalinas em diferentes regiões, que interferem diretamente na possibilidade de detecção do estro. De fato, a observação de estros é um fator que pode dificultar a implementação de programas de inseminação convencionais em bubalinos.

Associada à dificuldade de observação de cios, o estresse térmico pode desencadear reações fisiológicas nas búfalas, levando à baixa fertilidade. A influência do período do dia na concepção foi observada por Baruselli (1994), o qual detectou concepção em $72,22 \%$ das inseminações realizadas pela manhã, contra apenas $46,29 \%$ de concepção nas inseminações efetuadas à tarde, o que levou à conclusão que o estresse calórico ao qual o animal é submetido durante o dia pode ser responsável pela baixa concepção nos períodos da tarde. Também na Índia a concepção é mais alta $(40,1 \%)$ em baixas temperaturas do que durante os períodos de temperaturas moderadas $(38,1 \%)$ e altas $(12,6 \%)$ (Jain e Tailor, 1995). Esse fato foi confirmado por Srivastava e Sahni (1999), que encontraram percentagens de prenhez de $31,17 \%$ na estação chuvosa e $11,11 \%$ na estação seca e quente, com a 
incidência de estro mais alta na estação chuvosa (54,22\%) e mais baixa na estação seca e quente $(19,20 \%)$.

Efeitos do estresse térmico sobre a fisiologia reprodutiva dos machos

Não somente as fêmeas sofrem com o estresse térmico. Os machos também têm seu comportamento sexual afetado pelo calor ambiental, exprimindo maior desejo de copular durante as horas mais amenas do dia. Segundo Ohashi et al. (1988), os machos bubalinos manifestam maior libido durante a noite, logo após o pôr do sol, ou ainda de madrugada.

Outro fator importante além da libido é a normalidade da espermatogênese. Para os mamíferos que possuem testículos alojados em escrotos pendulares, inclusive touros bubalinos, a espermatogênese normal é dependente da manutenção da temperatura testicular entre 2 e $6^{\circ} \mathrm{C}$ mais baixa que a temperatura corpórea. Sabe-se que existe um gradiente de temperatura no escroto e nos testículos, que aumenta quanto mais distante estiver a estrutura relativamente à cavidade abdominal. É bem conhecido que um aumento da temperatura testicular diminui a qualidade do sêmen produzido (Waites, 1970).

A composição química do sêmen bubalino também sofre variações ao longo do ano. Mohan et al. (1994) detectaram concentrações de 568,53 mg\% de frutose, 5,27 g\% de proteínas totais, $74,13 \mathrm{~g} \%$ de colesterol total, 13,59\% de fosfato inorgânico, $115,87 \mathrm{mg} \% \mathrm{q} / \mathrm{L}$ de sódio e $22,7 \mathrm{mg} \% \mathrm{q} / \mathrm{L}$ de potássio na composição química do sêmen de búfalos adultos criados na Índia, e, portanto, mantidos em ambiente tropical. A congelabilidade média do sêmen desses búfalos, representada pela porcentagem de espermatozóides vivos após a descongelação, foi de 38,39 $\pm 1,42 \%$, e apresentou correlação positiva com o valor de proteínas totais no sêmen. Na região sudeste do Brasil, segundo Oba et al. (1994), o perfil bioquímico do sêmen de bubalinos varia ao longo do 
ano todo. No final do outono local (maio), quando as temperaturas são mais amenas, o sêmen bubalino apresenta concentrações de frutose e ácido cítrico (526,51 mg\% e 549,22 mg\%, respectivamente) maiores que a média anual, sendo esses elementos importantes para o metabolismo espermático e para o processo de criopreservação. Em maio, as concentrações de sódio e potássio $(122,54 \mathrm{mEq} / \mathrm{L}$ e $16,23 \mathrm{mEq} / \mathrm{L}$, respectivamente) ficam abaixo da média do ano (Oba et al., 1994).

O efeito negativo da temperatura ambiente sobre a qualidade seminal pode ser resultante da indução de degeneração testicular. Essa patologia é ocasionada, entre muitos fatores, por qualquer processo que determine a elevação da temperatura dos testículos, como, por exemplo, a dermatite escrotal, o excesso de gordura escrotal, edema, periorquite e elevação da temperatura ambiente com conseqüente estresse térmico (Nascimento e Santos, 2003). Segundo Skinner e Louw (1966), a temperatura ambiente crítica para prejuízo da espermatogênese está entre $27^{\circ} \mathrm{C}$ e $32^{\circ} \mathrm{C}$, e exposições contínuas a temperaturas excedendo os $30^{\circ} \mathrm{C}$ podem determinar marcante efeito negativo sobre a produção espermática.

Os ejaculados de machos com degeneração testicular de média intensidade apresentam baixa concentração espermática, baixa motilidade e número moderado de células com defeitos morfológicos, como gotas protoplasmáticas proximais, diadema, vacúolos e outros defeitos nucleares (Wenkoff, 1988).

O manejo diferenciado de touros bubalinos pode ser uma estratégia interessante para preservar a produção e a qualidade seminal de búfalos criados em ambiente tropical, principalmente para animais considerados de elite.

\section{Considerações Finais}

Pode-se minimizar os efeitos das elevadas temperaturas das regiões tropicais sobre esses animais por meio de: 
a) Otimização do ambiente oferecido às búfalas em lactação através de algumas práticas de manejo:

1 Disponibilizar sombra para as búfalas - o sombreamento pode ser provido por árvores (sombreamento natural) ou abrigos (sombreamento artificial). No caso do sombreamento natural, indica-se a utilização de árvores com copa frondosa e alta (3m, no mínimo);

2 Disponibilizar água nas horas mais quentes do dia - as búfalas devem ser submetidas à aspersão com água fria, regularmente. A água conduz o calor da superfície corporal para o ambiente, levando à maior evaporação da umidade da pele, permitindo que haja a utilização do resultante calor latente de vaporização para os resfriamento do corpo. Isto faz com que diminuam as compensações induzidas pelo calor como o decréscimo na ingestão de alimentos, alterações hormonais e outros fatores que resultam na redução da produção de leite;

3 Hora das ordenhas - trabalhos experimentais demonstram que quando a temperatura do ar é superior a $25^{\circ} \mathrm{C}$, os animais pastam bastante das 6 às 10 horas da manhã e reduzem o pastoreio das 10 às 16 horas, quando procuram sombra. Recomenda-se que as ordenhas sejam efetuadas em períodos de menor intensidade de pastejo, em locais com ventilação adequada. Entre as ordenhas, as búfalas devem ter acesso à sombra, com água e alimento suficientes.

\section{REFERENCIAS BIBLIOGRÁFICAS}

Ablas, D.S.; Titto; E.A.L.; Titto, C.G.; Cunha, T.M.; Pereira, A.M.F., 2007. Comportamento de bubalinos a pasto frente a disponibilidade de sombra e água para imersão. Ciência Animal Brasileira, vol.8, n², 167-176, 2007. 
AZEVEDO, M. Efeitos do verão e inverno sobre os parâmetros fisiológicos de vacas mestiças Holandês-Zebu, em lactação, na região de Coronel Pacheco, MG. 2004. 85p. Tese (Doutorado em Ciência Animal). Escola de Veterinária, Universidade Federal de Minas Gerais, Belo Horizonte.

Baruselli PS. Reprodução em búfalos, 1993. Disponível em: http://www.fmvz.usp.br/menu/sitebra11.html. Acesso em 28 ago 2008.

BLACKSHAW, J.K. \& BLACKSHAW, A.W. Heat stress in cattle and the effect of shade on production and behavior: a review. Australian Journal of Experimental Agriculture. $v$. 34, p.285-295, 1994.

Campanile, G, Neglia, G, Di Palo, R, Gasparrini, B, Pacelli, C, D’occhio, MJ, Zicarelli, L. 2006. Relationship of body condition score and blood urea and ammonia to pregnancy in Italian Mediterranean buffaloes. Reprodution Nutrition and Development, 46:57-62.

Cassiano, LAP, Mariante AS. McManus, C, Marques, JRF, Costa, NA. 2003. Caracterização fenotípica de raças bubalinas nacionais e do tipo Baio. Pesquisa Agropecuária Brasileira, 38:1337-1342

CHIKAMUNE, T.; KANAI, Y \& SHIMIZU, H. Comparison of the effects of seasonal-climatic changes on thermoregulatory responses and plasma concentrations of thyroid hormones in swamp buffaloes and cattle. Japanese Journal Zootecheny Science. v.57, n.9, p.778$784,1986$.

CHUTIKUL, K. Ruminant (Buffalo) nutrition. In: The asiatic water buffalo. Food and Fertilizer Technology Center for the Asian and Pacific Region. Taiwan, p.23-35, 1975.

COSTA, L. A. ÍNDICES DE CONFORTO TÉRMICO E ADAPTABILIDADE DE FÊMEAS BUBALINAS EM PASTEJO NO AGRESTE DE PERNAMBUCO. 2007. 52 p. Tese (Mestrado em Zootecnia) Universidade Federal Rural de Pernambuco, Recife.

CUNNINGHAM, J. G. (Ed.) Tratado de fisiologia veterinária. Rio de Janeiro: GuanabaraKoogan, 1993.

DOLLAH, M.A. \& ROBERTSHAW. Relationship between skin colour and sweating rate in regulation of body temperature in swamp buffaloes subjected to heat and sudden cooling. 
In: WORLD BUFFALO CONGRESS, 3. 1991, Sofia, Proceedings... Sofia, International Buffalo Federation. 1991. v.1. 227p.

FAO (Roma, Itália). O búfalo. Brasília: Ministério da Agricultura/São Paulo: Associação Brasileira de Criadores de Búfalos, 1991. 320p. (FAO. Série Produção Animal e Saúde, 4).

Garcia, A. R., Influência de fatores ambientais sobre as características reprodutivas de búfalos do rio (Bubalus bubalis) Rev. de Ciênc. Agrár. no 45, jan./jun.2006.

Guimarães, C. M et al. Termorregulação em bubalinos submetidos a duas temperaturas de ar e duas proporções de volumoso: Concentrado. Tese (Mestrado em Zootecnia). Universidade Federal de Lavras, Lavras - MG.

HARVEY, D. Some aspects of the importance of buffaloes as farmstock. Nutrition Abstract and Reviews, Farnham Royal, v.33, p.931-936, 1963.

Hegazy, MA, Essawy, AS, Teleb, HM, El-Wishy, AA, Youssef, AH. Effect of body condition score on reproductive performance of buffaloes. In: Proceedings do $4^{\circ}$ World Buffalo Congress, 1994, São Paulo, Brasil. São Paulo: ABCB. pp. 630-631.

HEMSWORTH, P.H.; BARNETT, J.L.; BEVERIDGE, L.; et al. The welfare of extensively managed dairy cattle: a review. Applied Animal Behaviour Science, v.42, p.161-182, 1995.

LOYPETJRA, P.; CHAIYABUTR,N.; USANAKORNKUL, S.; ICHAICHARNARONG, A. Water buffalo. In: Bioclimatology and the adaptation of livestock - World Animal Science. Disciplinary Approach B5. Ed. JOHNSON, H.D. Amsterdam, Elsevier, p.107-125, 1987.

MACHADO FILHO, L.C.P; BONIN, J.A.; GABE, D.O. et al. Estudo preliminar do comportamento de pastoreio de bufalinhos (Bubalus bubalis). In: Reunião Anual da SBZ, 25, 1989, Porto Alegre. Anais... Porto Alegre, SBZ. 1989, p.236.

MARAI, I. F. M.; HABEEB, A. A .M. Adaptability of Bos taurus cattle under hot arid conditions. Annals of Arid Zone, v. 37, n. 3, p. 253-281, 1998.

MARQUES, J.R.F.; CARDOSO, L.S. A bubalinocultura no Brasil e no mundo. In: OLIVEIRA, 
G.J.C. de; ALMEIDA, A.M.L. de; SOUZA FILHO, U.A. O búfalo no Brasil. Cruz das Almas: UFBA, 1997. p.7-42.

Marques, JRF. 1991. Avaliação genético-quantitativa de algumas características do desempenho produtivo de grupos genéticos de búfalos (Bubalus bubalis L.). Botucatu, São Paulo [em português]. Botucatu, Brasil: Universidade Estadual Paulista. Tese de Doutorado.

MASON, I.L. Environmental physiology. In: The husbandry and health of the domestic buffalo. Rome. W. Ross Cockrill. FAO. p.89-104, 1974.

MISRA, M.S.; SENGUPTA, B.P. \& ROY, A. Physiological reactions of buffalo cows maintained in two different housing conditions during summer months. Indian Journal of Dairy Science, v.16. p.203-215, 1963.

Nascimento, EF, Santos, RL. 2003. Patologia da reprodução dos animais domésticos. 2. ed. Rio de Janeiro, Brasil: Guanabara Koogan. 137p.

NRC. NATIONAL RESEARCH COUNCIL. The water buffalo; new prospects for an underutilized animal. National Academy Press. Washington D.C. 1981. 113p.

Oba, E, Amstalden, M, Santos, JEP, Bonfim, SRM, Emílio, S. Seasonal variations of chemical attributes in buffalo semen. In: Proceedings do $4^{\circ}$ World Buffalo Congress, 1994, São Paulo, Brasil. São Paulo: ABCB. pp. 576-578.

Ohashi, OM, Sousa, JS, Vale, WG. 1988. Aspecto reprodutivo do macho bubalino. In: Vale, WG. (Coord.). Bubalinos: fisiologia e patologia da reprodução. Campinas, Brasil: Fundação Cargill. pp. 69-86.

PANT, H.C.; ROY, Y.A. El bufalo de agua y su futuro. In: Bases biológicas de la producción animal en zonas tropicales. Editorial Acribia, Zaragoza. p.567-600, 1982.

Reichert, RH, Pires, RML, Martinez, AC, Baruselli, PS. Desempenho reprodutivo de búfalos da raça Murrah. In: Anais do $4^{\circ}$ Congresso Brasileiro de Buiatria, 2001, Campo Grande, Brasil. Campo Grande: [s.n.]. pp.104.

Ribeiro, HFL. Característica do manejo reprodutivo em búfalos na Amazônia. In: Anais do 
$1^{\circ}$ Congresso Brasileiro de Especialidades em Medicina Veterinária, 2002, Curitiba, Brasil. Curitiba: [s.n.]. pp.101-104.

Sampaio Neto, JC, Martins Filho, R, Lobo, RNB, Tonhati, H. 2001. Avaliação dos desempenhos produtivo e reprodutivo de um rebanho bubalino no Estado do Ceará. Revista Brasileira de Zootecnia, 30:368-373.

SILVA, R.G. Introdução à bioclimatologia animal. São Paulo: Nobel, 2000.

SHAFIE, M.M Environmental effects on water buffalo production. <http://www.fao.org/ag/againfo/resources/documents/WAR/war/V1650B/v1650b0a.htm.> Acesso em 01 set. 2005.

Skinner, JD, Louw, GN. 1966. Heat stress and spermatogenesis in Bos indicus and Bos taurus cattle. Journal of Applied Physiology, 21:1784-1790.

Srivastava, SK, Sahni, KL. 1999. Effect of season on oestrus and conception in village cows and buffaloes. Indian Veterinary Journal, 76:385-387.

Souza Jr, J.B.F. Fluxo de calor latente e mecanismos termorregulatórios em bovinos no semi-árido. PUBVet, Londrina, V. 2, N. 28, Jul 3, 2008. Disponível em: <http://www.pubvet.com.br/texto. php?id=282>. Acesso em: 02/09/2008.

TITTO, E. A.L. Clima - influência na produção de leite: ambiência na produção de leite em clima quente. Piracicaba: FEALQ, 1998.

Titto, EAL, Velloso, L, Zanetti, MA, Cresta, A, Toledo, LRA, Martins, JH. 1998. Teste da tolerância ao calor em novilhos Nelore e Marchigiana. Revista Portuguesa de Zootecnia, 5:67-70.

TULLOCH, D.G. \& LITCHFIELD, R.T. Wallows for Buffalo. Aust. Wildl. Res., v.8, p.555-65, 1981.

Vale, WG, Ribeiro, HFL. 2005. Características reprodutivas dos bubalinos: puberdade, ciclo estral, involução uterina e atividade ovariana no pós-parto. Revista Brasileira de Reprodução Animal, 29:63-73. 
Souza Júnior, J.B.F., Domingos, H.G.T., Silva, R.B. et al. Termorregulação em búfalos manejados em ambiente tropical. PUBVET, Londrina, V. 2, N. 41, Art\#396, Out3, 2008.

VILLARES, J.B.; RAMOS, A. de A.; ROCHA, G.P. As vias cutâneas e respiratórias na termólise de bubalinos sob extrema tensão térmica. In: RAMOS, A. de A.; VILLARES, J.B.; MOURA, J.C. de. Bubalinos. Campinas: Fundação Cargill, 1979. p.55-68.

Waites, GMH. 1970. Temperature regulation and the testis. In: Johnson, AD, Gomes, WR, Vandermark, NL. (Ed.). The testis. Nova Iorque, EUA: Nova Iorque Academic Press. pp. 241-279.

Wenkoff, MS. 1988. The evaluation of bulls for breeding soundness. Ontário, Canadá: Canadian Veterinarian Medical Association, pp. 48. 